\title{
Plumstone Ileus as a Presentation of Crohn's Disease
}

\author{
Catherine Elizabeth Western
}

Received: 24 May 2010 /Accepted: 31 May 2010 /Published online: 12 June 2010

(C) 2010 The Society for Surgery of the Alimentary Tract

Keywords Fruit stone - Bowel obstruction . Inflammatory bowel disease

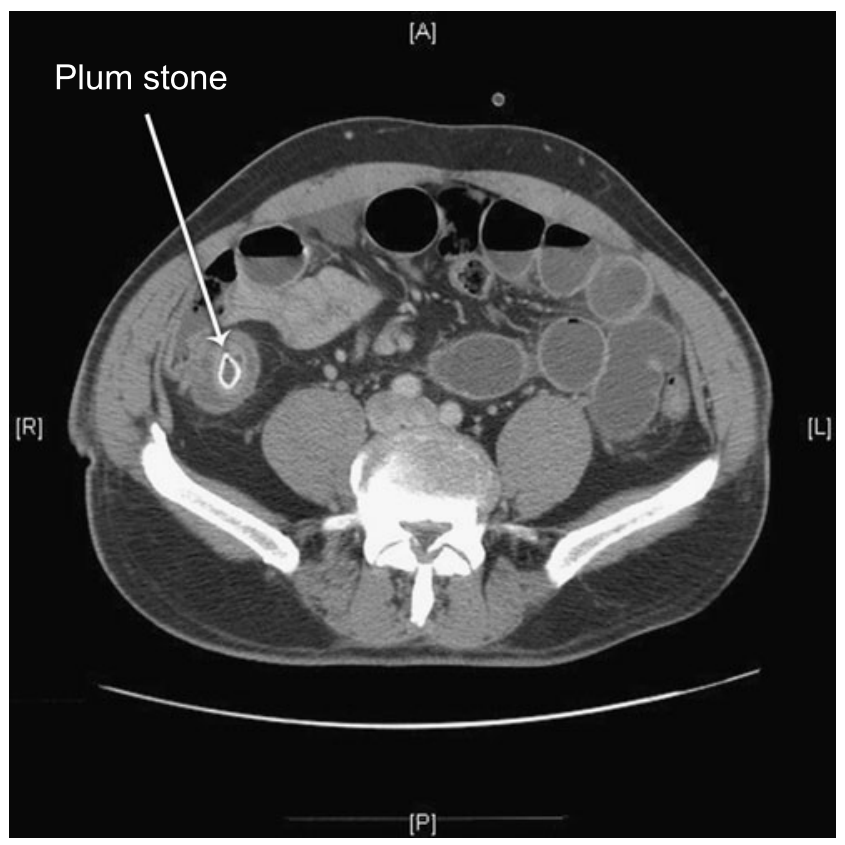

Fig. 1 CT abdomen demonstrating small bowel obstruction secondary to a plum stone.

\section{E. Western $(\bowtie)$}

Department of Colorectal Surgery,

The Royal Cornwall Hospital,

Treliske,

Truro, Cornwall TR1 3LJ, UK

e-mail: catherinewestern@nhs.net
This 57-year-old gentleman was admitted with colicky abdominal pain, vomiting and signs of small bowel obstruction on abdominal $\mathrm{X}$-ray. He confessed to swallowing a plum stone and so underwent laparotomy and enterotomy for plum stone ileus (Figs. 1 and 2). At laparotomy, fat-wrapping and other features consistent with Crohn's disease were noted in the region of impaction, but as he had been previously asymptomatic, no resection was undertaken. Unfortunately, he failed to settle and subsequently underwent right hemicolectomy, the histology from which confirmed Crohn's. On literature review, fruit stone impaction has been shown to be a not infrequent presentation of inflammatory bowel disease.

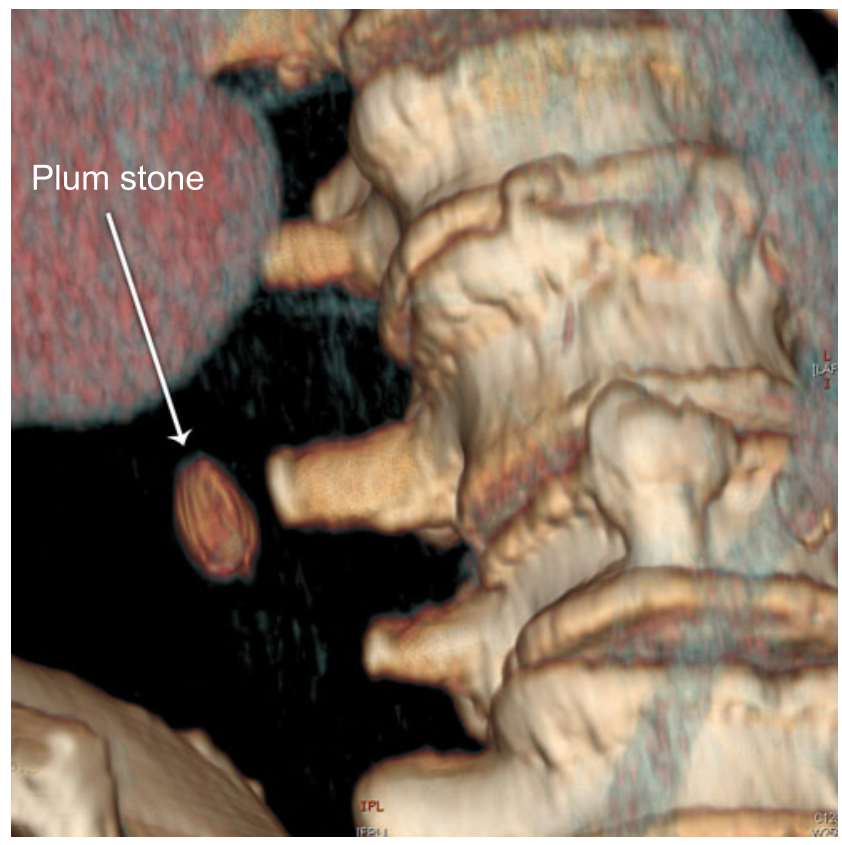

Fig. 2 CT reconstruction of plum stone position. 